IFN Working Paper No. 878, 2011

Endogenous Product Differentiation, Market Size and Prices

Shon Ferguson 


\title{
Endogenous Product Differentiation, Market Size and Prices ${ }^{* \dagger}$
}

\author{
Shon M. Ferguson ${ }^{\ddagger}$ \\ Research Institute of Industrial Economics \\ First Version: October 2008 \\ This Version: August 2011
}

\begin{abstract}
Recent empirical evidence suggests that prices for some goods and services are higher in larger markets. This paper provides a demand-side explanation for this phenomenon when firms can choose how much to differentiate their products in a model of monopolistic competition with horizontal product differentiation. The model proposes that consumers' love of variety makes them more sensitive to product differentiation efforts by firms, which leads to higher prices in larger markets. At the same time, endogenous product differentiation modeled in this way can lead to a positive and concave relationship between market size and entry.
\end{abstract}

JEL Classification Codes: D43, F12, L13.

Keywords: Endogenous Technology, Entry, Market Size Effect, International Trade, Monopolistic Competition.

\footnotetext{
${ }^{*}$ I thank Gregory Corcos, Karolina Ekholm, Rikard Forslid, Henrik Horn, Toshihiro Okubo Philippe Martin and seminar participants at Stockholm University, the Institute of Industrial Economics and the European Trade Study Group for valuable comments and suggestions. Financial support from the Social Sciences and Humanities Research Council of Canada (SSHRC) and the Marianne and Marcus Wallenberg Foundation is gratefully acknowledged.

$\dagger$ This paper was earlier circulated under the name "A Model of Ideal Differentiation and Trade".

${ }^{\ddagger}$ shon.ferguson@ne.su.se
} 
Conventional wisdom would suggest that prices should always be lower in larger markets as long as firms enter and competition becomes more intense. However, recent empirical evidence suggests that prices for some goods and services are in fact higher in larger markets. This evidence is at odds with mainstream models of differentiated goods in the literature, which generally predict that prices are lower in larger markets or that prices are unaffected by market size.

This paper provides an explanation for why prices can be higher in larger markets by assuming that firms can choose how much to differentiate their products. The basic model provides a simple tractable general equilibrium result, with the prediction that product differentiation increases with market size. Larger markets encourage product differentiation in the model because the "love of variety" property of the utility function. Love of variety leads individual consumers to consume more varieties and less of each variety in larger markets. I show that this behavior makes them more sensitive to firms' spending on product differentiation, with the prediction that products are more differentiated and sell at higher prices in larger markets. This prediction provides a possible explanation for the positive relationship between prices and market size found by Tabuchi and Yoshida (2000), Roos (2006) and Badinger (2007).

The theoretical model in this paper is based on monopolistic competition with endogenous technology choice. I assume that consumer utility follows a generalized CES utility function originating in Spence (1976). Following the endogenous sunk cost literature, I assume that firms can spend more on fixed costs in order to differentiate their product ${ }^{1}$. Firms choose their product differentiation spending from a continuum, with a more differentiated product requiring higher fixed cost spending. The fixed cost spending can be considered to be persuasive advertising or product development that differentiates one's own product from that of other firms. Firms then set prices

\footnotetext{
${ }^{1}$ This contrasts with most of the previous literature on trade and endogenous technology, such as Markusen and Venables (1997), Ekholm and Midelfart (2005) and Bustos (2010) assume a trade-off between lower marginal costs and higher fixed costs.
} 
via monopolistic competition.

The model outlined in this paper contributes to a new literature on how market size affects the extent of endogenous product differentiation. While there are several recent papers that deal with various aspects of product quality in differentiated goods markets $^{2}$, only a few predict that prices increase with market size ${ }^{3}$. The model here proposes a demand-side explanation for price differences between large and small markets due to firms' active investments in product differentiation ${ }^{4}$. My assumption of costly product differentiation contrasts with the models of monopolistic competition by Bertoletti, Fumagalli, and Poletti (2008), Lorz and Wrede (2009) and Zhelobodko, Kokovin, Parenti, and Thisse (2011) where product differentiation is costless.

The new result stemming from the assumption of costly product differentiation is that firm size can either increase or decrease as markets expand, depending on the responsiveness of consumers to firms' product differentiation spending. If consumers are sufficiently responsive to product differentiation spending then the model predicts a positive relationship between market size, firm size and prices, leading to a positive and concave relationship between market size and entry. Previous empirical studies typically interpret a concave relationship between market size and entry as a pro-competitive effect of market size. My framework suggests that market size and firm numbers alone do not provide sufficient information to make inferences about competition when product differentiation is endogenous and costly.

In the welfare analysis I show that product differentiation has two countervailing effects. While individuals like to consume varieties that are more differentiated,

\footnotetext{
${ }^{2}$ Prominent examples include Baldwin and Harrigan (2011), Simonovska (2010) and Khandelwal (2010).

${ }^{3}$ The model in this paper describes endogenous horizontal product differentiation, in contrast to the models of endogenous vertical differentiation in the Industrial Organization literature. Prominent examples include Shaked and Sutton (1987), Mazzeo (2002) and Berry and Waldfogel (2010).

${ }^{4}$ Helble and Okubo (2008) propose a supply-side explanation for higher prices in larger markets, whereby the home market effect bids up the price of skilled labor in the larger country, which increases quality and prices. Similarly, Tabuchi and Yoshida (2000) suggest that the productivity benefits of agglomeration can lead to higher wages, which increases rentals and hence leads to higher prices.
} 
there is also a negative effect due to higher price-cost markups. I am able to show, however, that the beneficial effect of product differentiation and variety outweighs the adverse effect of higher markups in larger markets. The model thus predicts that market size has an unambiguously positive effect on consumer welfare. I also compare the competitive equilibrium with the social optimum and show that the competitive equilibrium leads to an underinvestment in product differentiation compared to the social planner equilibrium. The social planner does not charge a markup, which allows it to differentiate products more than the competitive equilibrium.

I extend the basic model to include firm heterogeneity. In this case firms are assumed to vary with respect to their efficiency in differentiating their product, which leads to a distribution of prices in the economy and a lower bound on prices. In larger markets the least efficient firms with the lowest prices exit, which increases the lower bound price and hence the average price. I also extend the basic model to include two countries and trade costs. A new prediction regarding trade liberalization in this model is that price-cost markups and fixed cost spending is highest at an intermediate level of per-unit trade costs. The intuition behind this result is that firms' total trade costs are greatest when per-unit trade costs are at an intermediate level. Since a lower elasticity of substitution reduces the negative impact of total trade costs on export demand, firms have the strongest incentive to differentiate their product and reduce their substitution elasticity when total trade costs make up the largest proportion of firms' output. The model thus predicts that prices can either rise or fall with trade liberalization. This result can help to make sense of the mixed evidence concerning whether prices fall when trade liberalizes, as is found by Revenga (1997), Trefler (2004) and Feenstra (2006). The prediction that the elasticity of substitution is decreasing with market size and trade costs can also reconcile the Broda and Weinstein (2006) finding that elasticities of substitution have decreased over time.

The rest of the paper is organized as follows: The basic model in a closed economy 
and the effect of market size on product differentiation, entry and welfare are presented in Section 1. A comparison of the competitive solution to the social optimum is given in Section 2. Firm heterogeneity is added to the model in Section 3. The model is expanded to include two countries and trade costs in Section 4. Conclusions follow in Section 5 .

\section{Basic Model}

I begin by describing the model in a closed economy. The economy is composed of a continuum of monopolistically competitive firms $N$ indexed by $i \in[0, N]$ and there is no strategic interaction between firms. The representative consumer is endowed with one unit of labor.

\subsection{Consumer Preferences:}

The representative consumer's utility maximization problem for differentiated goods is defined as:

$$
\max _{c_{i}} U=\left(\int_{0}^{N} c_{i}^{\theta_{i}} d i\right)^{\frac{1}{\theta_{m}}} \quad \text { s.t. } \int_{0}^{N} p_{i} c_{i} d i=w
$$

where $c_{i}$ is the quantity of good $i$ consumed by the representative consumer. The utility for differentiated goods is based on the generalized CES utility function by Spence (1976), where $\theta_{i} \in(0,1)$ is a firm-specific parameter that determines the price elasticity of demand for good $i .^{5} \quad \theta_{m} \in(0,1)$ is a preference parameter that is not firm-specific. $p_{i}$ is the price of good $i$ and $w$ is the representative consumer's wage. The demand for a good by a representative consumer is thus:

\footnotetext{
${ }^{5}$ Since $\theta_{i}$ is a parameter in the consumer's utility function it may be argued that it is not observable. I assume that firms are able to invest in product differentiation, which is assumed to have a mapping into $\theta_{i}$.
} 


$$
c_{i}\left(p_{i}, \sigma_{i}, N, \mu, \lambda\right)=\frac{w\left(\frac{M^{1-\theta_{m}}}{\theta_{m} \lambda} \frac{\theta_{i}}{p_{i}}\right)^{\frac{1}{1-\theta_{i}}}}{\int_{0}^{N} p_{i}\left(\frac{M^{1-\theta_{m}}}{\theta_{m} \lambda} \frac{\theta_{i}}{p_{i}}\right)^{\frac{1}{1-\theta_{i}}} d i}
$$

where $\lambda$ is the representative consumer's marginal utility of income. One can also derive an expression for the marginal utility of income:

$$
\lambda=\frac{M^{1-\theta_{m}}}{\theta_{m}} \frac{\theta_{i} c_{i}^{\theta_{i}-1}}{p_{i}} .
$$

As in Krugman (1979), firms will take $\lambda$ as given.

\subsection{Technology:}

\subsubsection{Production Technology}

Labor is the only input in this economy, and each firm's total labor requirement $l_{i}$ includes an endogenously determined fixed labor cost $F_{i}$, and an exogenous variable amount of labor cost $\beta$ in the production process:

$$
l_{i}=F_{i}+\beta x_{i}
$$

where $x_{i}$ is the total quantity demanded of good $i$.

\subsubsection{Endogenous Product Differentiation}

The model in this paper assumes that the fixed cost, $F_{i}$, is a function of the preference parameter $\sigma_{i}$ and imposes the following assumption:

\section{ASSUMPTION 1:}

For all $\theta_{i} \in(0,1)$,

$$
F_{i}=F_{i}\left(\theta_{i}\right)
$$


is twice continuously differentiable in $\theta_{i}$, with the following properties:

$$
F_{i}^{\prime}\left(\theta_{i}\right)<0, F_{i}^{\prime \prime}\left(\theta_{i}\right)>0, \lim _{\theta_{i} \rightarrow 0^{+}} F_{i}\left(\theta_{i}\right)=\infty, \lim _{\theta_{i} \rightarrow 1^{-}} F_{i}\left(\theta_{i}\right)=0
$$

The assumption is simply that costs are increasing in product differentiation and convex.

The concept that fixed costs affect a consumer preferences follows the work of Sutton (1991). Differentiating one's own product from others (i.e. lowering the preference parameter, $\theta_{i}$ ) requires higher fixed costs. These fixed costs could be persuasive advertising or product development that differentiates a firm's own product from that of other firms. I do not assume a functional form at the moment, only that it is upward sloping and convex as $\theta_{i}$ decreases, so that fixed cost spending exhibits decreasing returns. I later assume a particular function form for $F_{i}\left(\theta_{i}\right)$ which satisfies all of these properties and allows for an analytical solution, but many properties can be shown with this more general assumption. I refer to (5) as the "advertising function" throughout the rest of the paper.

\subsubsection{Markup Pricing}

Firms enter, then they choose their optimal level of product differentiation, then they set prices via monopolistic competition. The equilibrium is found by backward induction. Each firm sets price in order to maximize profit, and takes endogenous fixed costs, $F_{i}$, as given:

$$
\pi_{i}=p_{i} x_{i}-w \beta x_{i}-w F_{i}\left(\theta_{i}\right)
$$

Firms maximize (6) with respect to $p_{i}$, yielding following first order condition:

$$
p_{i}=\frac{w \beta}{\theta_{i}} .
$$


One thus obtains markup pricing, with a constant markup for a given $\theta_{i}$. The markup is endogenous, however, since $\theta_{i}$ is an endogenous variable chosen by the firm. Firms will take (7) into consideration when choosing $\theta_{i}$.

\subsubsection{Optimal Product Differentiation}

Each firm chooses their preference parameter, $\theta_{i}$, to maximize operating profits less the fixed cost to differentiate. Firm $i$ 's demand is the sum of consumer demands, $x_{i}=L c_{i}$, where $L$ is the number of consumers in the economy. Operating profits are concave in $\theta_{i}$, so a maximum exists as long as $F_{i}\left(\theta_{i}\right)$ is chosen such that profits are non-negative. Using (2), the demand for firm $i$ 's product is:

$$
x_{i}\left(p_{i}, \sigma_{i}, N, \mu, L, \lambda\right)=\frac{L w\left(\frac{M^{1-\theta_{m}}}{\theta_{m} \lambda} \frac{\theta_{i}}{p_{i}}\right)^{\frac{1}{1-\theta_{i}}}}{\int_{0}^{N} p_{i}\left(\frac{M^{1-\theta_{m}}}{\theta_{m} \lambda} \frac{\theta_{i}}{p_{i}}\right)^{\frac{1}{1-\theta_{i}}} d i} .
$$

Firms take $\lambda$, the marginal utility of income, and the denominator in (8) as given when setting their preference parameter. The first order condition for product differentiation is derived by substituting (7) and (8) into (6), then maximizing firm profits with respect to $\theta_{i}$ :

$$
\left(p_{i}\left(\theta_{i}\right)-w \beta\right) x_{i}\left(p_{i}, \theta_{i}\right)\left[\begin{array}{c}
\frac{1}{\left(1-\theta_{i}\right)^{2}} \ln \left(\frac{M^{1-\theta_{m}}}{\theta_{m} \lambda} \frac{1}{w \beta}\right) \\
+\frac{2}{\left(1-\theta_{i}\right)^{2}} \ln \theta_{i}+\frac{1}{\left(1-\theta_{i}\right) \theta_{i}}
\end{array}\right]=w F^{\prime}\left(\theta_{i}\right)
$$

Note that (9) equates the marginal revenue and marginal cost of increasing $\theta$, which explains why both sides of (9) are negative. Given Assumption 1, the marginal cost of product differentiation increases and approaches infinity as $\theta$ decreases towards zero. 


\subsubsection{Equilibrium with Identical Firms}

The rest of this section assumes that firms are identical, meaning that they will all choose the same level of product differentiation. Firms enter until profits equal zero for each firm. Combining the markup pricing condition, (7), and the zero profit condition, $p=w \beta+w F / x$, one obtains an expression for output per firm:

$$
x(\theta)=\frac{F(\theta)}{\beta} \frac{\theta}{1-\theta} .
$$

The functional form of $F(\theta)$ can be chosen such that $x(\theta)$ is an increasing, decreasing, or constant function of $\theta$.

The full employment of labor condition determines the number of firms in the manufacturing industry:

$$
N=\frac{\mu L}{F(\theta)+\beta x}
$$

Overall, equations (3), (5), (7), (9), (10) and (11) make up the basic model. This includes the same equations as Krugman (1980) for profit maximization in price, zero profits, and full employment of labor, plus (3), (5) and (9). The unknowns are $p, x$, $N, \sigma, F$, and $\lambda$.

The next lemma establishes that firms choose a unique level of product differentiation that maximizes their profit, which holds under very general assumptions about the nature of the advertising function.

Lemma 1 Suppose that Assumption 1 holds and firms set prices via monopolistic competition. Then for a large enough $L$ there exists a unique symmetric equilibrium value of $\theta$ with positive fixed cost spending given by the following expression:

$$
\frac{F(\theta)}{1-\theta}\left[\ln \left(\frac{\frac{F(\theta)}{\beta} \frac{\theta}{1-\theta}}{L}\right)+\frac{1}{\theta}\right]=F^{\prime}(\theta) .
$$

Proof. See appendix. 
Equation (12) provides an implicit solution for the equilibrium level of product differentiation, $\theta$, which is a function of market size $L$, marginal $\operatorname{cost} \beta$ and the form of the advertising function.

\subsection{Market Size Effects}

The model predicts that firms' spending on product differentiation is affected by market size, which has important implications for prices and entry. The next proposition describes how market size affects equilibrium product differentiation.

Proposition 1 Suppose that Assumption 1 holds. Then product differentiation is increasing in market size, i.e.:

$$
\frac{d \theta}{d L}<0
$$

Proof. See appendix.

The intuition for this result falls directly from the love-of-variety property of the generalized CES utility function. The elasticity of substitution affects the concavity of utility for each variety and a greater concavity of utility increases consumers marginal utility of consumption at low levels of consumption. Larger markets encourage product differentiation because consumers consume more varieties and less per variety per capita. Consumers thus move down their utility curves for each variety and become more sensitive to firms' spending on product differentiation. The market size effect on $\theta$ affects all of the other endogenous variables in the model. As market size increases, fixed cost spending will accordingly increase via the relationship specified in equation (5). Prices rise via the markup pricing rule (7).

The prediction that prices are higher in larger markets has been confirmed by several studies. Tabuchi and Yoshida (2000) find that doubling city size in Japan reduces real wages by approximately $7-12 \%$, while Roos (2006) finds that consumer prices are higher in regions of Germany with larger populations. Badinger (2007) finds that the European Union's Single Market Program led to lower markups in 
manufacturing and construction but higher markups in service industries.

This new evidence on the pattern of prices does not square with any workhorse models of monopolistic competition in the International Trade and New Economic Geography literature ${ }^{6}$. However, it is related to recent theoretical contributions in the Industrial Organization literature, such as Amir and Lambson (2000) and Chen and Riordan (2007, 2008).

The prediction that prices increase in market size is the opposite conclusion of the "ideal variety" approach to modeling monopolistic competition, whether product differentiation is exogenous as in Lancaster $(1979,1980)$ or endogenously determined as in Weitzman (1994). The reason for this discrepancy is that product differentiation imposes a disutility on consumers in the Ideal Variety approach, while it enhances consumers' utility in the "love of variety" approach. Adding endogenous product differentation in the manner described above can thus provide a very different result compared to previous models.

The predictions here are relevant for goods with a propensity for endogenous product differentiation, which explains why it conficts with the evidence from the market for ready-mixed concrete by Syverson (2004). Ready-mixed concrete is a homogeneous product, which makes switching between suppliers easier when markets are more dense. In contrast, my framework deals with markets for differentiated products, and going without a particular good is more difficult in larger markets because goods are more differentiated.

The relationship between the number of firms, market size and product differen-

\footnotetext{
${ }^{6}$ The intra-industry trade models of Krugman (1980) and Helpman and Krugman (1987) employ Dixit and Stiglitz (1977) preferences and exhibit no market size or distance effect on prices. The heterogeneous firm model by Melitz (2003) exhibits no market size effects and average export prices that are decreasing in distance. Models based on Melitz and Ottaviano (2008) assume quadratic utility and exhibit "pro-competitive effects", whereby markups and hence prices are lower in larger markets due to greater competition. Models based on Baldwin and Harrigan (2011) exhibit the desired characteristic that higher-priced goods are sold to more distant countries, but lack any market size effect.
} 
tiation can be seen by substituting (10) into (11):

$$
N=\frac{L(1-\theta)}{F(\theta)} .
$$

Equation (13) illustrates that the effect of market size on variety depends not only on the direct effect of $L$ but also on $F$ and $\theta$. In contrast to Krugman (1980), the number of firms need not increase linearly with market size. It is unclear whether product differentiation has a positive or negative effect on entry without making a further assumption about the functional form of $F(\theta)$. However, one can make a more precise statement about how variety changes with market size by totally differentiating (13) with respect to $L$ :

$$
\frac{d N}{d L}=\frac{1-\theta}{F(\theta)}(1 \underbrace{-\frac{\theta}{1-\theta} \frac{d \theta}{d L} \frac{L}{\theta}+\frac{\theta F^{\prime}(\theta)}{F(\theta)} \frac{d \theta}{d L} \frac{L}{\theta}}_{\text {Effect of endogenous product differentiation }})
$$

One can see in (14) that variety is affected by market size via three distinct channels. The first channel is the linear relationship between market size and variety that occurs when product differentiation is exogenous. The second channel is the effect of market size on variety via product differentiation, which is positive since Proposition 1 showed that $d \theta / d L$ is negative. The third channel is the effect of market size on variety due to fixed cost spending, which depends on the elasticity of the advertising function and the market size effect on product differentiation. The third channel is negative since $F^{\prime}(\theta)$ is negative by Assumption 1. While the first channel is the linear relationship between market size and entry found in Krugman (1980), other two channels capture the two countervailing effects of product differentiation on variety. On the one hand, product differentiation on its own has positive effects on variety, but the fixed costs associated with increasing product differentiation reduces variety by leading to fewer larger firms. These effects can be summarized in the following proposition: 
Proposition 2 If the advertising function is sufficiently inelastic then firm size increases with market size and entry increases with market size.

$$
\begin{gathered}
\frac{d l(\theta)}{d L} \gtrless 0 \Leftrightarrow \frac{\theta F^{\prime}(\theta)}{F(\theta)} \lessgtr-\frac{\theta}{1-\theta} \\
\frac{d N}{d L} \gtrless 0 \Leftrightarrow 1-\frac{d \theta}{d L} \frac{L}{\theta}\left(\frac{\theta}{1-\theta}-\frac{\theta F^{\prime}(\theta)}{F(\theta)}\right) \gtrless 0
\end{gathered}
$$

Proof. See appendix.

The results in Proposition 2 infer that endogenous product differentiation can lead to a positive and concave relationship between market size and entry if firm size increases with market size. The relationship between firm size and market size depends on the elasticity of the advertising function. If the advertising function is sufficiently elastic then firms are induced to spend more on product differentiation as the market grows to such an extent that they increase in size, which leads to a concave relationship between entry and market size. This result contrasts with the oligopoly framework by Bresnahan and Reiss (1991) that infers increased competition and lower markups when entry is increasing and concave in market size. For example, Campbell and Hopenhayn (2005) found that retailing firms are larger in larger cities, and concluded that firms were larger due to falling markups in larger markets, although the authors had no direct evidence on markups. My framework suggests, however, that market size and firm numbers or firm size alone do not provide sufficient information to make inferences about competition. The endogenous sunk cost literature argues a similar point. In contrast to Sutton (1991), however, my framework predicts an anti-competitive market size effect without requiring a high concentration of firms. This result differs from the model by Zhelobodko, Kokovin, Parenti, and Thisse (2011), which predicts that firm size increases with market size only in the pro-competitive case. Including a fixed cost to differentiate means that firm size is increasing with market size even in the anti-competitive case. 


\subsection{An Analytical Solution}

One can fully solve the basic model using a specific functional form for $F\left(\theta_{i}\right)$. I thus impose:

\section{ASSUMPTION 2:}

$$
F(\theta)=\alpha \frac{1-\theta}{\theta}, \quad \theta \in(0,1)
$$

This functional form has all of the properties in Assumption 1. Using Assumption 2 we can find an analytical solution to the system of equations (3) - (11):

$$
\begin{gathered}
p=\frac{w \beta}{2} \ln \left(\frac{\beta L}{\alpha}\right) \\
x=\frac{\alpha}{\beta} \\
N=L \frac{2}{\alpha \ln \left(\frac{\beta L}{\alpha}\right)} \\
\theta=\frac{2}{\ln \left(\frac{\beta L}{\alpha}\right)} \\
F=\alpha \frac{\ln \left(\frac{\beta L}{\alpha}\right)-2}{2}
\end{gathered}
$$

This particular formulation of the advertising function is tractable because it eliminates the problem of having a logged $\theta$ term in (9). One can see in (10) that this particular function has the unique property that $x=\alpha \beta^{-1}$, a constant.

The analytically solvable model is also characterized by product differentiation and prices increasing in $\beta$, the marginal cost parameter. Thus more expensive materials lead to higher prices and more product differentiation. 


\subsection{Welfare Effect of Market Size}

I use the direct utility function for manufactures, $M$, to examine the welfare effects of market size. In the symmetric equilibrium with $\theta_{m}=\theta$, and substituting (10) and (11) into (1) using $c=x / L$ provides an expression of utility in terms of market size and product differentiation:

$$
U(L, \theta)=L^{\frac{1}{\theta}-1}\left(\frac{1-\theta}{F(\theta)}\right)^{\frac{1}{\theta}} x(\theta)
$$

The direct effect of $L$ on utilty from manufactures is positive. The effect of product differentation on utility, however, is unclear because reductions in $\theta$ have two countervailing effects: utility becomes more concave in consumption, but prices increase as markups widen. This contrasts with Krugman (1980) that assumes exogenous technology, where prices are constant and welfare effects occur exclusively via increased variety. One can show, however, that utility is increasing as products become more differentiated and this leads to utility increasing in market size. These results are summarized in the following proposition:

Proposition 3 Utility per-capita is increasing in market size under the following condition:

$$
\frac{\partial U}{\partial \theta} \lessgtr 0 \Leftrightarrow \frac{\theta F^{\prime}(\theta)}{F(\theta)} \lessgtr \frac{1}{1-\theta} \ln \frac{L(1-\theta)}{F(\theta)} .
$$

Proof. See appendix.

Utility per-capita is increasing as products become more differentiated as long as the market size, $L$, is large enough. Endogenous product differentiation modeled in this way thus has a net positive effect on welfare when the market expands, despite the adverse effect of higher markups. 


\section{Competitive Equilibrium vs. Social Optimum}

An important task is to compare the level of product differentiation and variety provided in the competitive equilibrium with the social optimum. The social optimum is constrained only by the full employment condition and the technologies for producing the differentiated good and for differentiating these goods as defined by Assumption

1. The social planner maximizes the representative consumer's utility by choosing the optimal variety, output per firm and level of product differentiation in the differentiated goods industry, subject to the full employment of labor constraint and the advertising function:

$$
\max _{x, N, \theta} U[N v(N, \theta) x] \text { s.t. } N(F(\theta)+\beta x)=L
$$

where $v(N, \theta)$ represents the "taste for variety", which captures consumers' love of variety:

$$
v(N, \theta)=\frac{M_{N}(x, \ldots, x)}{M_{1}(N x)}=\frac{M_{N}(1, \ldots, 1)}{N}
$$

The concept of separating the love of variety effect from the markup condition originates in Benassy (1996). I extend Benassy's formulation so that the love of variety depends not only on the number of varieties but also on how differentiated they are from each other. Differentiating with respect to $x, N$, and $\theta$ yields, respectively:

$$
\begin{gathered}
U^{\prime}[v(N, \theta)]=\lambda \beta \\
U^{\prime}\left[x v(N, \theta)+x N \frac{\partial v}{\partial N}\right]=\lambda(F(\theta)+\beta x) \\
U^{\prime}\left[\frac{\partial v}{\partial \theta} x\right]=\lambda F^{\prime}(\theta)
\end{gathered}
$$


where $U^{\prime}$ is the partial derivative of $U$. The solutions to equations (18), (19) and (20) give $x^{o p t}, N^{o p t}$, and $\theta^{\text {opt }}$. Dividing (18) by (19) we obtain:

$$
\frac{\beta x}{F(\theta)+\beta x}=\frac{1}{1+\frac{\partial v}{\partial N} \frac{N}{v(N, \theta)}}
$$

This result, originating in Benassy (1996), illustrates how the socially optimal production decision depends crucially on consumer's love of variety. Dividing (18) and (19) by (20) respectively and combining these with (21) provides a new expression that describes the social planner's optimal choice of product differentiation:

$$
\frac{\frac{\partial v}{\partial \theta}}{\frac{\partial v}{\partial N}}=N \frac{F^{\prime}(\theta)}{F(\theta)}
$$

The social planner sets the optimum level of product differentiation where the marginal rate of substitution between product differentiation and variety equals the percentage change in the cost to differentiate all available goods.

Comparing the social planner and competitive equilibrium is eased by assuming a particular utility function. In the case of CES utility the love of variety expression is $v(N, \theta)=N^{\frac{1}{\theta}-1}$. Plugging this into (22) pins down the socially optimal level of product differentiation:

$$
\frac{F(\theta)}{1-\theta}\left[\frac{1}{\theta} \ln \frac{F(\theta)}{L(1-\theta)}\right]=F^{\prime}(\theta)
$$

Comparing equations (12) and (23), it is difficult to say without making further assumptions whether the competitive equilibrium differentiates products more or less than the social optimal. The difference between these equations illustrates, however, that the social optimal and competitive equilibrium need not be equivalent. One can show, however, that the competitive equilibrum results in less than the socially optimal product differentiation when the advertising function is given by Assumption 
2 if $\beta L>\alpha$. This result, although dependent upon a particular advertising function, illustrates a key property of the model. The social planner does not charge a markup, which allows it to differentiate products more than is possible in the competitive equilibrium.

\section{$3 \quad$ Firm Heterogeneity}

The basic model can easily be extended to capture product differentiation heterogeneity across firms. The profit of firm $i$ is:

$$
\pi_{i}=\left(p_{i}\left(\theta_{i}\right)-w \beta\right) x_{i}\left(p_{i}, \theta_{i}\right)-w F_{i}\left(\theta_{i}, \alpha_{i}\right)
$$

where $\alpha_{i}$ is a parameter that determines the firm's efficiency in product differentiation. A lower $\alpha_{i}$ makes the firm more efficient in differentiating its product. Following Melitz (2003), firms draw their efficiency parameter from a random distribution. Since operating profits are concave in $\theta_{i}$ this means that low-efficiency firms will make negative profits and leave the market. The "cutoff" firm $D$ with an efficiency draw $\alpha_{D}$ such that is indifferent between leaving the market and remaining earns zero profits:

$$
\left(p_{D}\left(\theta_{D}\right)-w \beta\right) x_{D}\left(p_{D}, \theta_{D}\right)=w F_{D}\left(\theta_{D}, \alpha_{D}\right)
$$

The first order condition for the cutoff firm is given by:

$$
\frac{F_{D}\left(\theta_{D}\right)}{1-\theta_{D}}\left[\ln \left(\frac{\frac{F\left(\theta_{D}\right)}{\beta} \frac{\theta_{D}}{1-\theta_{D}}}{L}\right)+\frac{1}{\theta_{D}}\right]=F_{D}^{\prime}\left(\theta_{D}\right)
$$

As given by Proposition 1 and abstracting from general equilibrium effects, a larger market will be characterised by a cutoff firm with a greater degree of differentiation. This model thus predicts that higher-priced goods are sold in larger markets. 


\section{Two Countries and Trade Costs}

\subsection{Setting, Preferences and Technology}

Extending the basic model to a two country model with trade costs yields new results regarding firms' technology choice and the pattern of trade. There are two industries: a differentiated goods industry $M$ characterized by increasing returns to scale and a constant returns industry $A$. Preferences and the firms' problem are otherwise identical to the basic model. I assume that iceberg trade costs between the two countries, whereby $\tau$ units must be shipped in order for one unit to arrive at its destination. I assume that the markets are of equal size and that firms are identical. Moreover, I normalize the price of the agricultural good to unity, which equalizes the wage in both country. These simplifications allow us to more easily see the effect of trade costs on equilibrium product differentiation.

\subsection{The Trade Friction Effect}

The effect of trade costs on the equilibrium level of product differentiation is a unique property of the model. The first order condition for product differentiation under the special case where country sizes are identical (i.e. $L=L^{*}$ ) is:

$$
\underbrace{\frac{F(\theta)}{1-\theta}\left[\ln \left(\frac{\frac{F(\theta)}{\beta} \frac{\theta}{1-\theta}}{L\left(1+\tau^{\frac{1}{1-\theta}}\right)}\right)+\frac{1}{\theta}\right]}_{\text {"market size effect" }}-\underbrace{\frac{F(\theta)}{(1-\theta)^{2}}\left[\frac{\tau^{\frac{1}{1-\theta}} \ln \tau}{1+\tau^{\frac{1}{1-\theta}}}\right]}_{\text {"trade friction effect" }}=F^{\prime}(\theta) .
$$

This equation effectively divides the first order condition into two parts, a "market size effect" and a "trade friction effect". The "market size effect" is almost identical to the left hand side of the first order condition in the basic model, (9), except for the additional term $1+\tau^{\frac{1}{1-\theta}}$ multiplying $L$ in the denominator. This term equals 1 under infinite trade costs and 2 under free trade, since free trade between two countries of 
equal size effectively doubles the market.

The "trade friction effect" is an additional term that is not present in the first order condition under autarky. If trade costs per unit are zero or infinite then no trade occurs and the trade friction effect will disappear. This term is positive for intermediate trade costs, reaching a single maximum. The marginal revenue of decreasing $\theta$ is thus maximized at some intermediate level of trade costs. Trade frictions thus affect more than just market potential in the model; the friction itself enhances the marginal revenue of product differentiation. The intuition is that lowering $\theta$ abates the loss of demand due to "melting", and the marginal benefit from this activity is greatest when "melting" is greatest (i.e. intermediate trade costs).

It can be helpful to analyze this result within a trade liberalization context. If trade costs are gradually lowered from autarky to free trade, $\theta$ first decreases, then increases as trade costs approach zero. Similarly, $F$ and $p$ first increase to a maximum at some intermediate level of trade costs, then decrease as trade costs approach zero. This contrasts with the monotonic market size effects that one observes in the basic closed economy model. The result that product differentiation effects are strongest at intermediate trade costs is akin to new economic geography literature, where agglomeration forces are strongest at intermediate trade costs.

When trade costs are low the model predicts that prices increase with distance, which agrees with the export price literature, such as Baldwin and Harrigan (2011) and Ottaviano and Mayer (2008). The result that the elasticity of substitution is decreasing can also reconcile the Broda and Weinstein (2006) result that the elasticity of substitution has been trending downwards at the same time as the process of "globalization" has expanded markets and reduced trade barriers. 


\section{Conclusion}

The model presented in the paper takes a new look at product differentiation in a model of monopolistic competition. Moreover, the model has several attractive features that agree with recent empirical findings on the pattern of prices within and across countries. Prices are higher in larger countries and regions and prices increase with distance.

The model allows for firms to endogenously choose from a continuous set of technologies by creating a trade-off between fixed costs and product differentiation. This assumption is consistent with fixed costs that represent persuasive advertising or product development that differentiate one's own product from others in the eyes of consumers. Fixed costs, markups, and output per firm are increasing functions of market size, a characteristic that agrees with the literature. The model thus generates "endogenous markups" that are a direct result of firms' optimizing behavior.

The mechanism of endogenous product differentiation described in this paper may be part of the reason why we do not always see pro-competitive effects in differentiated goods markets. This model can be applied to many issues, including growth, trade, and economic geography. The prediction that markups increase with market size may be considered somewhat controversial, since the "conventional wisdom" is that markups will decrease as market size increases, firms enter, and the competition becomes tougher. However, the recent empirical evidence on prices suggests that procompetitive effects of market size need not hold, especially in differentiated products. As Jean Tirole (1988, p.289) puts it, "Though it will be argued that advertising may foster competition by increasing the elasticity of demand (reducing "differentiation"), it is easy to find cases in which the reverse is true." It is hoped that this paper has given some theoretical foundation to this argument. 


\section{References}

Amir, R. and V. E. Lambson (2000, April). On the effects of entry in cournot markets. Review of Economic Studies 67(2), 235-54.

Badinger, H. (2007). Has the EU's single market programme fostered competition? testing for a decrease in markup ratios in EU industries. Working Papers 135, Oesterreichische Nationalbank (Austrian Central Bank).

Baldwin, R. and J. Harrigan (2011). Zeros, quality and space: Trade theory and trade evidence. Technical report, American Economic Journal: Microeconomics (forthcoming).

Benassy, J.-P. (1996). Taste for variety and optimum production patterns in monopolistic competition. Economics Letters 52(1), 41-47.

Berry, S. and J. Waldfogel (2010). Product quality and market size. Journal of Industrial Economics 58(1), 1-31.

Bertoletti, P., E. Fumagalli, and C. Poletti (2008). On price-increasing (monopolistic) competition. Technical report, Mimeo, Università di Pavia.

Bresnahan, T. F. and P. C. Reiss (1991). Entry and competition in concentrated markets. Journal of Political Economy 99(5), 977-1009.

Broda, C. and D. E. Weinstein (2006). Globalization and the gains from variety. The Quarterly Journal of Economics 121(2), 541-585.

Bustos, P. (2010). The impact of trade on technology and skill upgrading evidence from Argentina. American Economic Review (forthcoming).

Campbell, J. R. and H. A. Hopenhayn (2005). Market size matters. Journal of Industrial Economics 53(1), 1-25.

Chen, Y. and M. H. Riordan (2007). Price and variety in the spokes model. Economic Journal 117(522), 897-921. 
Chen, Y. and M. H. Riordan (2008). Price-increasing competition. RAND Journal of Economics 39(4), 1042-1058.

Dixit, A. K. and J. E. Stiglitz (1977). Monopolistic competition and optimum product diversity. American Economic Review 67(3), 297-308.

Ekholm, K. and K. H. Midelfart (2005). Relative wages and trade-induced changes in technology. European Economic Review 49(6), 1637-1663.

Feenstra, R. C. (2006). New evidence on the gains from trade. Review of World Economics (Weltwirtschaftliches Archiv) 142(4), 617-641.

Helble, M. and T. Okubo (2008). Heterogeneous quality firms and trade costs. Policy Research Working Paper Series 4550, The World Bank.

Helpman, E. and P. Krugman (1987). Market Structure and Foreign Trade: Increasing Returns, Imperfect Competition, and the International Economy, Volume 1 of MIT Press Books. The MIT Press.

Khandelwal, A. (2010). The long and short (of) quality ladders. Review of Economic Studies 7r7(4), 1450-1476.

Krugman, P. R. (1979). Increasing returns, monopolistic competition, and international trade. Journal of International Economics 9(4), 469-479.

Krugman, P. R. (1980). Scale economies, product differentiation, and the pattern of trade. American Economic Review 70(5), 950-59.

Lancaster, K. (1979). Variety, equity, and efficiency: product variety in an industrial society. Columbia University Press New York.

Lancaster, K. (1980). Competition and product variety. Journal of Business 53(3), S79-103.

Lorz, O. and M. Wrede (2009). Trade and variety in a model of endogenous product differentiation. The B.E. Journal of Economic Analysis \& Policy 9(1). 
Markusen, J. R. and A. J. Venables (1997). The role of multinational firms in the wage-gap debate. Review of International Economics 5(4), 435-51.

Mazzeo, M. J. (2002). Product choice and oligopoly market structure. RAND Journal of Economics 33(2), 221-242.

Melitz, M. and G. Ottaviano (2008). Market size, trade, and productivity. Review of Economic Studies 75(1), 295-316.

Melitz, M. J. (2003). The impact of trade on intra-industry reallocations and aggregate industry productivity. Econometrica 71 (6), 1695-1725.

Ottaviano, G. and T. Mayer (2008). The happy few: the internationalisation of European firms. Number 18 in Blueprints. Bruegel.

Revenga, A. (1997). Employment and wage effects of trade liberalization: The case of mexican manufacturing. Journal of Labor Economics 15(3), S20-43.

Roos, M. W. M. (2006). Regional price levels in Germany. Applied Economics 38(13), 1553-1566.

Shaked, A. and J. Sutton (1987). Product differentiation and industrial structure. Journal of Industrial Economics 36(2), 131-46.

Simonovska, I. (2010). Income differences and prices of tradables. Working Papers 1015, University of California, Davis, Department of Economics.

Spence, M. (1976). Product selection, fixed costs, and monopolistic competition. Review of Economic Studies 43(2), 217-35.

Sutton, J. (1991). Sunk Costs and Market Structure: Price Competition, Advertising, and the Evolution of Concentration. MIT Press.

Syverson, C. (2004). Market structure and productivity: A concrete example. Journal of Political Economy 112(6), 1181-1222. 
Tabuchi, T. and A. Yoshida (2000). Separating urban agglomeration economies in consumption and production. Journal of Urban Economics 48(1), 70-84.

Tirole, J. (1988). The Theory of Industrial Organization. Number 0262200716. The MIT Press.

Trefler, D. (2004). The long and short of the Canada-U. S. Free Trade Agreement. American Economic Review 94(4), 870-895.

Weitzman, M. L. (1994). Monopolistic competition with endogenous specialization. Review of Economic Studies 61(1), 45-56.

Zhelobodko, E., S. Kokovin, M. Parenti, and J.-F. Thisse (2011). Monopolistic competition in general equilibrium: Beyond the CES. Working Paper 2011-08, Paris School of Economics.

\section{A Mathematical Appendix}

\section{A.1 Proof of Lemma 1:}

Substitute (3) and (10) into (9) and rearrange to obtain (12). The right hand side of (12) is negative and monotonically increasing in $\theta$ by Assumption 1 . If $L$ is sufficiently large then the left hand side of (12) is negative.

\section{Proof of Proposition 1:}

Totally differentiating and rearranging (12) we obtain an expression for the effect of market size on product differentiation:

$$
\frac{d \theta}{d L}=\frac{\frac{1}{L} \frac{F(\theta)}{1-\theta}}{\frac{\partial}{\partial \theta}\left(\frac{F(\theta)}{1-\theta}\left[\ln \left(\frac{\frac{F(\theta)}{\beta} \frac{\theta}{L}}{L}\right)+\frac{1}{\theta}\right]\right)-F^{\prime \prime}(\theta)}
$$


The denominator is negative by Assumption 1 and since operating profits are concave in $\theta$. Thus $d \theta / d L<0$.

\section{Proof of Proposition 2:}

The result for firm size is found by substituting (10) into (4) and rearranging. The result for firm entry is obtained rearranging (14). Inspection of (15) and (16) reveals that if $d l(\theta) / d L>0$ then $d N / d L>0$.

\section{Proof of Proposition 3:}

It is clear from (17) that $\partial M / \partial L>0 . \partial \theta / \partial L<0$ due to Proposition 1. The partial derivative of indirect utility with respect to $\theta$ is:

$$
\frac{\partial U}{\partial \theta}=-\frac{1}{\theta \beta}\left(\frac{L(1-\theta)}{F(\theta)}\right)^{\frac{1-\theta}{\theta}}\left(\ln \frac{L(1-\theta)}{F(\theta)}+\frac{\theta F^{\prime}(\theta)}{F(\theta)}(1-\theta)\right)
$$

In order for indirect utility to be decreasing in $\theta$ the following condition must hold:

$$
\frac{\partial U}{\partial \theta} \lessgtr 0 \Leftrightarrow \frac{\theta F^{\prime}(\theta)}{F(\theta)} \lessgtr \frac{1}{1-\theta} \ln \frac{L(1-\theta)}{F(\theta)} .
$$

This will hold a long as $L$ is large enough. 